\title{
WHATSAPP: A TOOL FOR ADHERENCE TO ASYMPTOMATIC CHRONIC-DISEASE DRUG THERAPIES?
}

\author{
Amanda Caroline Sartori ${ }^{1, a}$, Julio de Souza Sá ${ }^{1, a}$, Marcelo Picinin Bernuci ${ }^{2, b}$, Ely Mitie Massuda ${ }^{2, b}$, \\ Tiago Franklin Rodrigues Lucena ${ }^{2, b}$ and Mirian Ueda Yamaguchi ${ }^{2, b}$ \\ ${ }^{1}$ Unicesumar-Cesumar University Center, Guedner Ave, 1610, Maringá, Paraná, Brazil \\ ${ }^{2}$ Unicesumar-Cesumar University Center, Health Promotion Graduate Program \\ and ICETI - Cesumar Institute of Science, Tecnology and Inovation, \\ Guedner Ave, 1610, Maringá, Paraná, Brazil \\ ${ }^{a} \mathrm{MSC}$ \\ ${ }^{b} \mathrm{PhD}$
}

\begin{abstract}
Studies have shown that mobile health (mHealth) technologies are increasingly being successfully used in control programs for symptomatic diseases, such as cancer and HIV, as methods of behavioral intervention to enhance patient adherence to treatments. The objective of this research was to evaluate the potential of WhatsApp messages as an intervention method to improve adherence to the treatment of two asymptomatic diseases: hypertension and diabetes. A controlled trial was conducted with 499 participants from the basic health units of Maringá, Paraná, Brazil. They received 58 WhatApp messages over three months with information about the importance of adherence to drug therapy. Adherence to the therapy was assessed by the Morisky-Green test (MGT). The analysis of the efficacy of the intervention was performed by comparing the MGT test results before and after the messages were sent. The results showed an expressive difference in adherence to the drug therapy for the group that received the WhatsApp messages (67.5\%) compared to those who did not receive them $(58.5 \%)$. However, in contrast to our expectations, there was no significant association between adherence and the intervention group. WhatsApp can be used as a welfare technology in various health-related areas, however it was concluded that, for asymptomatic diseases, mHealth technology interventions can be useful if associated with other strategic processes.
\end{abstract}

\section{KEYWORDS}

mHealth, Drug-Therapy Compliance, Asymptomatic Diseases, Primary Health Care

\section{INTRODUCTION}

Chronic non-communicable diseases (CNDs) claim the lives of about 38 million people a year in the world. Among these diseases, diabetes mellitus (DM) and systemic arterial hypertension (SAH) are chronic diseases frequently asymptomatic and associated with low therapeutic adherence (Malta et al, 2017).

Interventions associated with mobile health (mHealth) technologies have the potential to change health behaviors. These technologies are devices easily introduced into individuals' daily lives (Aurora et al, 2014). Among the mHealth devices, smartphones are personal, portable and allow access to WhatsApp, which is a tool with good acceptance, reaching approximately one billion people nowadays (Ganasegeran et al., 2017). Studies have demonstrated that disease self-management interventions can positively influence the behavior in health (Free et al, 2013). In this context, the objective of this study was to carry out an intervention by means of sending messages through WhatsApp in order to improve adherence to antidiabetic and antihypertensive drug therapy. 


\section{METHODS}

A representative sample of 499 diabetic and hypertensive patients registered in the 33 basic-health units of Maringá city - Paraná, Brazil, participated in the present study. Data collection was performed during October 2017 to April 2018. The research was approved by the Research Ethics Committee No. 2,234,211, $8 / 23 / 2017$. Of the patients, 57 were diabetic, 280 were hypertensive and 162 had both diabetes and hypertension.

This study was conducted in three stages. In the first, the Morisky-Green Test (MGT), which consists of a self-report scale for assessing compliance with drug therapy, was applied to the intervention and control groups. The MGT test considers patients adherent when they reach a score of four in an instrument containing four objective questions, whose answers can be positive (yes - 0 points) or negative (no - 1 point) (Morisky et al, 1986).

In the second stage, 58 messages (text, audio and pictures) were sent by WhatsApp to the intervention group, using the platform BulkService ${ }^{\circledR}$. The content of the messages reported about protection and risk factors, signs and symptoms of diabetes or hypertension, the importance of their treatment, complications of the diseases, reminders to take medication and motivational content. After the intervention, at the third stage of the study, telephone contact was made with all the 499 patients included in the research (intervention and control groups), and the MGT was applied again, in order to identify the effectiveness of sending the messages via Whatsapp.

\section{RESULTS}

One-third of the individuals that participated in the survey (33.0\%) were between 50 and 59 years old, and the average of all the patients was 56.88 years of age. The mean was lower among those interviewed who had only one disease, 53.05 years for diabetics and 56.34 years for hypertensives, and higher among those who had both diseases: 59.17 years. Regarding sex, the majority (65.0\%) were women; however, the distribution between the sexes was approximately equal for those who only had diabetes, but among the hypertensive patients, women $(70.0 \%)$ predominated. The majority were white $(79.0 \%)$, married $(63.0 \%)$ and the most frequent level of schooling was incomplete secondary education, reported by about a third of respondents.

The proportions of adherent patients at the time before the interventions were very similar between the groups, $38.3 \%$ and $39.1 \%$, and there was no significant difference in adherence (p-value of 0.927 ) before the intervention (Table 1). On the other hand, the difference in the proportion of adherence between the groups was greater after the intervention, $67.5 \%$ for the intervention group and $58.5 \%$ for the control group. However, there was no significant association between adherence and the intervention group. (p value of 0.077)

Table 1. Relative frequencies of adherents to the drug therapy and results of the chi-square test, to compare the responses between the intervention and control groups, before and after sending the messages by WhatsApp. Maringá, PR, Brazil, 2018

\begin{tabular}{ccccc}
\hline \multirow{2}{*}{ Time } & \multicolumn{2}{c}{ Adherence frequency (\%) } & \multicolumn{2}{c}{ Result of $\chi^{2}$ teste } \\
\cline { 2 - 5 } & Intervention group & Control group & $\chi^{2}$ & p value \\
\hline Before intervention & $38.3 \%$ & $39.1 \%$ & 0.008 & 0.927 \\
After intervention & $67.5 \%$ & $58.5 \%$ & 3.117 & 0.077 \\
\hline
\end{tabular}

\section{CONCLUSION}

The present study showed an expressive difference in the proportion of adherence to the drug therapy for the group that received the WhatsApp messages compared to those who did not receive them. However, statistically there was not sufficient sample evidence to indicate the association between adherence and the group after the intervention. In view of the complexity of adherence to drug use for generally asymptomatic 
diseases like hypertension and diabetes, it can be concluded that WhatApp, as a mHealth-technology intervention, may be useful if it is associated with other strategies. Health-education processes to improve literacy in users' health and / or relationships of trust between patient and health professionals, could be associated to combat low adherence to drug therapies. The importance of the control group's result in this study must be highlighted, which could identify a possible phenomenon known as 'social desirability bias', which refers to the fact that interviewees report behavior that they believe represents an acceptable social position (Nolte et al, 2013). This phenomenon may have influenced the interviewees to report greater adherence for both groups (the intervention and control groups). Finally, a future study should be considered, including clinical controls by measuring the blood pressure of hypertensive patients and the blood glycemic concentration for diabetic patients before, during and after sending messages by WhatsApp.

\section{REFERENCES}

Arora, S. et al. (2014). Trial to examine text message-based mHealth in emergency departamento patients with diabetes (TExT-MED): A randomized controlled trial. Annals of Emergency Medicine, 63(6), 745-754.

Free, C., Phillips, G., Galli, L. (2013). The effectiveness of mobile-health technology-based health behaviour change or disease management interventions for health care consumers: A systematic review. Plos Med, 10(1), 1-45.

Ganasegeran, K. et al. (2017). The -Health revolution: Exploring perceived benefits of WhatsApp use in clinical practice. International Journal of Medical Informatics, 97(1), 145-151.

Malta, D.C et al. (2017). Doenças crônicas não transmissíveis e a utilização de serviços de saúde: análise da Pesquisa Nacional de Saúde no Brasil. Revista Saúde Pública, 51(1), 1-10.

Morisky, D.E., Green, L.W., Levine, D.M. (1986). Concurrent and predictive validity of a self- reported measure of medication adherence. Medicine Care., 24, 67-74.

Nolte, S., Elsworth, G.R., Osborne, R.H., (2013). Absence of social desirability bias in the evaluation of chronic disease self-management interventions. Health and Quality of Life Outcomes, 11(114), 1-9. 